\title{
Optimizing care of your patients with COPD
}

\author{
This article was published in the following Dove Press journal: \\ Nursing: Research and Reviews \\ 21 January 2014 \\ Number of times this article has been viewed
}

\section{Chris Garvey' \\ Nicola A Hanania ${ }^{2}$ \\ Pablo Altman ${ }^{3}$ \\ 'Seton Pulmonary and Cardiac Rehabilitation, Daly City, CA, USA; ${ }^{2}$ Asthma Clinical Research Center, Section of Pulmonary, Critical Care and Sleep Medicine, Baylor College of Medicine, Houston, TX, USA; ${ }^{3}$ Mylan Specialty LP, Basking Ridge, NJ, USA (formerly)}

Correspondence: Chris Garvey Seton Pulmonary and Cardiac Rehabilitation, 1900 Sullivan Ave, Daly City, CA, USA 94015

$\mathrm{Tel}+\mathrm{I} 65099 \mid 6776$

Fax + I $65099 \mid 6775$

Email chrisgarvey@dochs.org
Abstract: Chronic obstructive pulmonary disease (COPD) is now the third-leading cause of death in the US. The primary risk factor for COPD is smoking. COPD is underdiagnosed, and spirometry, the main method for its diagnosis, is underutilized. Nurses can play an essential role in improving patient outcomes, in part by helping to apply clinical guidelines for care. Management of COPD consists of reduction of risk factor exposure (for example, smoking cessation), influenza vaccination, pharmacotherapy, and pulmonary rehabilitation. Comorbidities may pose a special challenge in patients with COPD and they may compete with COPD for attention during office visits. Of particular note with regard to pharmacotherapy is the choice of delivery system. Handheld inhalers form the mainstay of treatment of COPD; however, some patients have difficulty using inhalers because of an inability to generate sufficient inspiratory flow, impaired manual dexterity, or cognitive impairment that leads to difficulties in following instructions concerning how to use the inhaler. In such patients, nebulization may be an effective alternative. In this review, we provide a list of best practices that can assist nurses in the optimal care of patients with COPD.

Keywords: chronic obstructive pulmonary disease, exacerbation, long-acting beta-agonist, bronchodilators, nebulization

\section{Introduction}

Chronic obstructive pulmonary disease (COPD) is a major public health problem that has a significant impact on patients, caregivers, and health care systems. In 2008, COPD was responsible for 3.28 million deaths, or $5.8 \%$ of the overall worldwide mortality. ${ }^{1}$ Worldwide deaths from COPD are expected to increase $>30 \%$ in the next decade unless risk factors can be modified. ${ }^{2}$ In 2008, COPD became the third-leading cause of death in the US, surpassing cerebrovascular diseases and trailing only heart disease and cancer. ${ }^{3}$ Furthermore, COPD in the US is responsible for significant morbidity, with 739,000 hospitalizations and 15.4 million physician office visits in $2009 .{ }^{4}$

The demographics of COPD in the US are also changing with regard to sex. In 2000, the number of women dying of COPD exceeded the number of men for the first time. ${ }^{5}$ And indeed in 2010, the prevalence among women was higher than among men within all racial groups, except in blacks $\geq 65$ years of age. ${ }^{4}$ While the exact reason for this increase in prevalence of COPD among women is unknown, it has been attributed to increased tobacco use. ${ }^{2}$ Furthermore, any smoker above the age of 40 years may be at risk of COPD; it is not restricted to older people, as once perceived. In addition to the changing demographics, COPD is now recognized as a systemic disease that is 
associated with multiple comorbidities, including cardiovascular, musculoskeletal, and psychological disease. ${ }^{6}$

While COPD presents many challenges, the good news is that this is a treatable disease. Nurses can play a pivotal role in improving the lives and health outcomes of patients with this disease through attentive interactions and choosing the right management approach.

In this review, we will discuss the evidence-based guidelines for the pharmacological and nonpharmacological management of COPD, and outline the challenges and barriers that clinicians may face in implementing such guidelines. ${ }^{7}$ Such challenges and barriers include poor patient adherence to treatment, clinician utilization of guidelines, and timely management of exacerbations and the multiple comorbidities associated with the disease.

\section{Overview of COPD}

COPD is characterized by persistent airflow limitation, disease progression over time, and exacerbations and comorbidities that contribute to severity. ${ }^{7}$ The older terms, emphysema (destruction of lung parenchyma) and chronic bronchitis (chronic cough and sputum production), are now combined under the umbrella of COPD, with the relative contribution of each differing by patient. ${ }^{2,7}$ The primary risk factor of COPD is tobacco smoking. ${ }^{2}$ While COPD cannot be cured, its disabling symptoms can often be controlled and disease progression can be slowed through proper interventions, especially smoking cessation. $^{2}$

\section{Diagnosis and management of COPD}

Any person who smokes, is $\geq 40$ years of age, and has respiratory symptoms such as cough, shortness of breath, or activity limitations may have COPD, and should be offered spirometry testing to confirm or rule out the disease. ${ }^{7}$ COPD often goes undiagnosed and is, therefore, untreated. ${ }^{2,5}$ The underdiagnosis of COPD may be related to its slow progression and its subtle symptoms, which may often be attributed to aging or other disorders. In addition, many patients underreport their symptoms to their health care providers. Furthermore, while the gold standard for diagnosing this condition is spirometry, many clinicians underutilize it, as illustrated by a study which demonstrated that only $32 \%$ of patients undergo this test at the time of diagnosis. ${ }^{8}$ Of note, spirometry results are also important to stage the severity of the disease. ${ }^{9}$ While there is no evidence to justify screening spirometry in all smokers above the age of 40 years, current recommendations stipulate that this test be done in those who are symptomatic. ${ }^{10}$ To help identify individuals who may benefit from spirometry, two questionnaires have been validated and are available for use. These questionnaires include the Lung Function Questionnaire ${ }^{11}$ and the COPD Population Screener ${ }^{12}$ (Figure 1A and B). Once the disease is confirmed, another questionnaire may be used to assess stability of the disease (COPD Assessment Test [CAT]; Figure 2). ${ }^{13}$

\section{Assessment and goals of management}

The goals of management for COPD include relieving symptoms, improving exercise tolerance and health status, reducing the risk of disease progression, and preventing exacerbation and mortality. ${ }^{7}$ Although guidelines for the diagnosis and management of COPD exist, many clinicians may not be familiar with or may not implement these guidelines in their practices, thus compromising patient care. ${ }^{14}$ The Global Initiative for Chronic Obstructive Lung Disease (GOLD) is an international group of renowned experts that has developed evidence-based guidelines for COPD management. ${ }^{7}$ The group recommends the use of validated questionnaires such as the CAT (Figure 2$)^{13}$ or the Medical Research Council dyspnea scale (Figure 3$)^{15}$ to assess symptoms. Patients with COPD should be classified as either low or high risk based on spirometry results (Table 1; GOLD 1 and 2 are considered low risk, and GOLD 3 and 4 are considered high risk). A history of exacerbations should also be used to assign risk, with low risk being defined as $\leq 1$ exacerbation per year and high risk being defined as $\geq 2$ exacerbations per year. It is important to note that the risk classification of a patient may be different for risk based on spirometry, as compared with risk based on exacerbation history. In that case, the higher risk category should be used. The classification system illustrated in Figure 4 is then used to categorize patients into four groups, with Group A having the least severe disease and Group D having the most severe disease. ${ }^{7}$ As shown in Table 2, the GOLD patient group classification should be used to guide pharmacotherapy in individual patients. ${ }^{7}$

\section{COPD exacerbations}

The course of COPD is often complicated by episodes of exacerbation of the disease. An exacerbation of COPD is defined as an acute worsening of symptoms beyond the day-to-day variability, leading to a change in medication. ${ }^{7}$ Exacerbations contribute to long-term decline in lung function ${ }^{16}$ and worsening health status. ${ }^{17}$ Exacerbations are 


\section{Lung Function Questionnaire \\ Do you suffer from breathing problems and/or frequent cough?}

These questions ask about your breathing problems and/or frequent cough. As you answer these questions, please think about how you are feeling physically when you are experiencing these symptoms. For each question, choose the one answer that best describes your symptoms. Share the answers with your doctor.

Step 1: Answer each question and write the score in the box provided next to it.

Step 2: Add the score boxes for your total score

Step 3: Take the test to the doctor to talk about your score

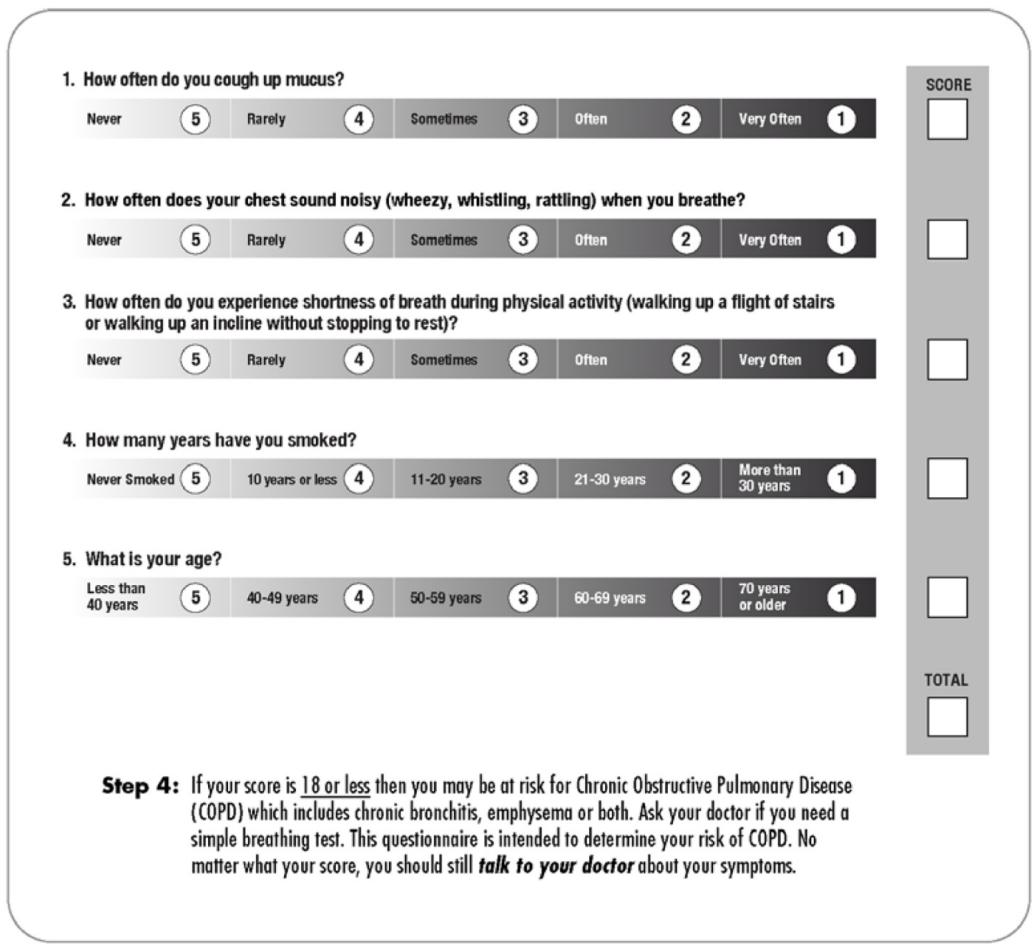

B

\begin{tabular}{|l|l|c|}
\hline Item & Response & Score \\
\hline During the past 4 weeks, how much of the time did you feel & None of the time & 0 \\
short of breath? & A little of the time & 0 \\
& Some of the time & 1 \\
& Most of the time & 2 \\
& All of the time & 2 \\
\hline Do you ever cough up any "stuff," such as mucus or phlegm? & No, never & 0 \\
& Occasionally (colds) & 0 \\
& Few days a month & 1 \\
& Most days a month & 1 \\
\hline Please select the answer that best describes you in the past & Yes, every day & 2 \\
\hline I months: & Strongly disagree & 0 \\
& Disagree & 0 \\
& Unsure & 0 \\
\hline Have you smoked at least 100 cigarettes in your entire & Agree & 1 \\
life? & Strongly agree & 2 \\
\hline How old are you? & No & 0 \\
& Yes & 2 \\
\hline Total score & Aged 35-49 years & 0 \\
\hline
\end{tabular}

Figure I Lung Function Questionnaire and self-scored COPD Population Screen Questionnaire.

Notes: (A) Lung Function Questionnaire. Data from Hanania et al." Reprinted with permission @ Copyright 2009 GlaxoSmithKline. All rights reserved. (B) Self-scored COPD Population Screen Questionnaire. Martinez FJ, Raczek AE, Seifer FD, et al, COPD-PS Clinician Working Group. Development and initial validation of a self-scored COPD Population Screener Questionnaire (COPD-PS). COPD, 2008;5(2):85-95, copyright () 2008, Informa Healthcare. Reproduced with permission of Informa Healthcare. ${ }^{12}$ Patients $(n=113)$ with spirometry-confirmed airway obstruction had a mean score ( \pm standard deviation) of $6.76 \pm 1.94$ on this questionnaire. Abbreviations: COPD, chronic obstructive pulmonary disease; $n$, number. 


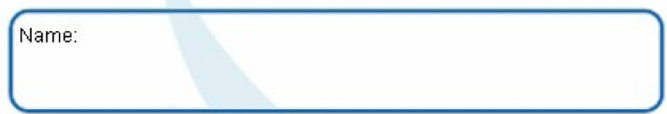

Today's Date:

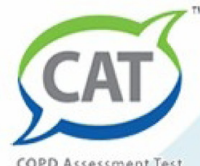

How is your COPD? Take the COPD Assessment Test (CAT)

This questionnaire will help you and your healthcare professional measure the impact COPD (Chronic Obstructive Pulmonary Disease)
is having on your wellbeing and daily life. Your answers and test score, can be used by you and your healthcare professional to help improve the management of your COPD and get the greatest benefit from treatment

If you wish to complete the questionnaire by hand on paper, please click here and then print the questionnaire.

If you complete the questionnaire on-line, for each question below, click your mouse to place a mark $($ in the box that best describes you currently.

Example: I am very happy (0) (3) (3) (3) (2) (3)

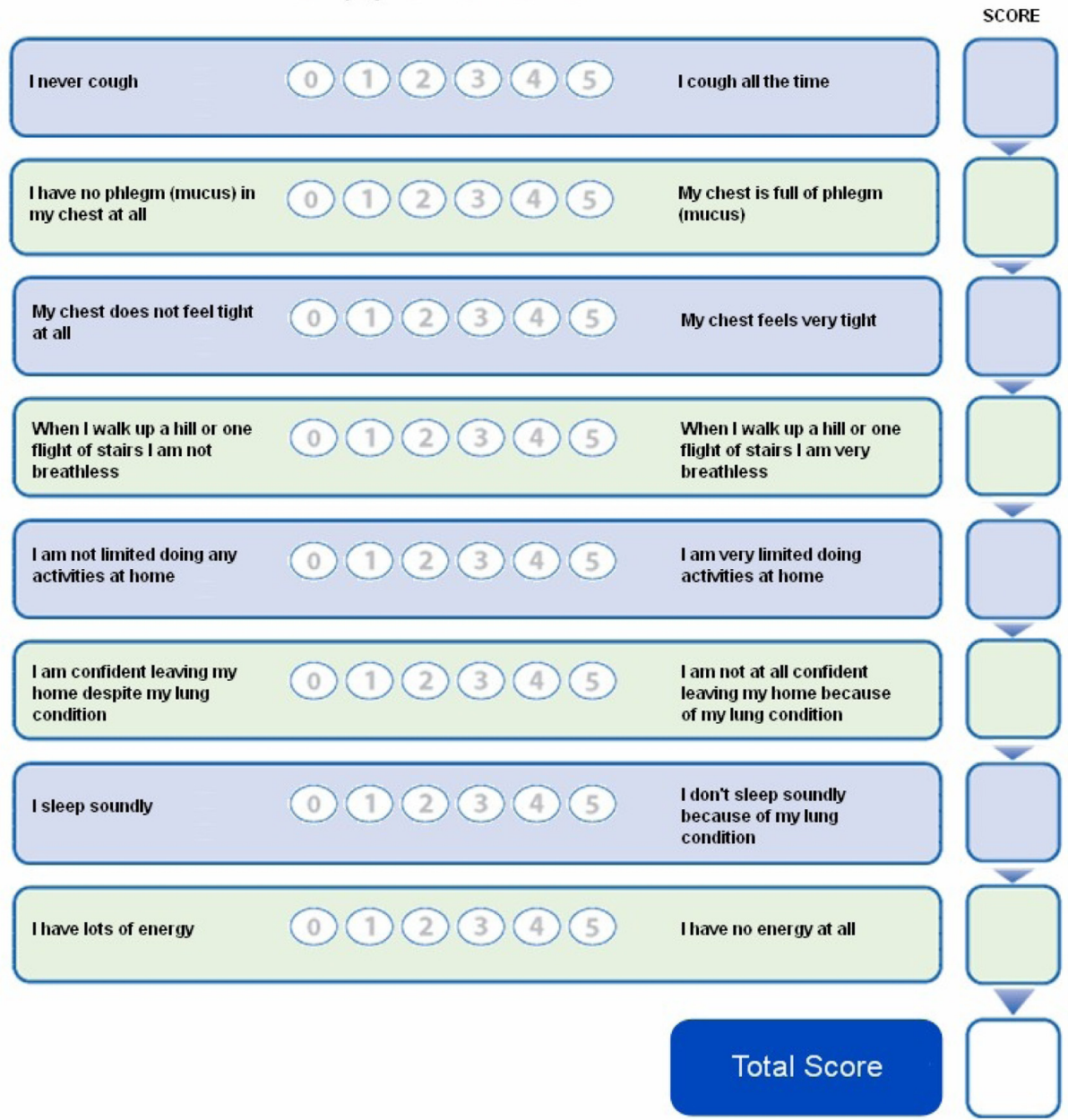

Figure 2 COPD Assessment Test. Data from Hones et al. ${ }^{13}$

Note: Copyright GlaxoSmithKline. Used with permission.

Abbreviation: COPD, chronic obstructive pulmonary disease.

often underreported by the patient, ${ }^{18}$ and current guidelines recommend educating patients about the signs and symptoms of exacerbation so that they will report their symptoms to health care workers. ${ }^{19} \mathrm{~A}$ history of exacerbation in the past year is the most important predictor of subsequent exacerbations. ${ }^{20}$ The goals of managing COPD exacerbations include minimizing the impact of the current exacerbation and preventing future episodes. ${ }^{7}$

\section{Management of COPD}

The management approach to $\mathrm{COPD}^{7}$ is based on three main components: nonpharmacological therapy of COPD 


\section{Please tick in the box that applies to you (one box only)}

mMRC grade 0 . I only get breathless with strenuous exercise

mMRC grade 1. I only get short of breath when hurrying on the level or walking up a slight hill

mMRC grade 2. I walk slower than people of the same age on the level because of breathlessness, or I have to stop for breath when walking on my own pace on the level

mMRC grade 3. I stop for breath after walking about 100 meters or after a few minutes on the level

mMRC grade 4. I am too breathless to leave the house or I am breathless when dressing or undressing

Figure 3 Modified Medical Research Council Questionnaire for Assessing the Severity of Breathlessness.

Note: From the Global Strategy for Diagnosis, Management, and Prevention of COPD, 2013, available from http://www.goldcopd.org. ${ }^{7}$ Used with permission. Abbreviation: mMRC, modified Medical Research Council.

(ie, reducing risk factors by implementing smoking cessation, reducing exposures to noxious stimuli, regular influenza and pneumococcal vaccinations, and the use of pulmonary rehabilitation [PR] in appropriate patients); pharmacological therapy of COPD; and management of comorbidities.

\section{Nonpharmacological therapy of COPD}

Given the critical role that smoking plays in the development of COPD, smoking cessation should be a high priority. It is important to note that smoking cessation at any age is beneficial. Of course, the earlier smoking cessation is

Table I Classification of the severity of airflow limitation in COPD (based on postbronchodilator FEV )

\begin{tabular}{lll}
\hline In patients with & $\mathbf{F E V}$ /FVC $<\mathbf{0 . 7 0}$ & \\
GOLD I & Mild & $\mathrm{FEV}_{1} \geq 80 \%$ predicted \\
GOLD 2 & Moderate & $50 \% \leq \mathrm{FEV},<80 \%$ predicted \\
GOLD 3 & Severe & $30 \% \leq \mathrm{FEV}_{1}<50 \%$ predicted \\
GOLD 4 & Very severe & $\mathrm{FEV}_{1}<30 \%$ predicted \\
\hline
\end{tabular}

Note: From the Global Strategy for Diagnosis, Management, and Prevention of COPD, 2013, available from http://www.goldcopd.org.7 Used with permission.

Abbreviations: COPD, chronic obstructive pulmonary disease; $\mathrm{FEV}_{\mathrm{l}}$, forced expiratory volume in I second; FVC, forced vital capacity; GOLD, The Global Initiative for Chronic Obstructive Lung Disease. achieved, the better. ${ }^{21} \mathrm{~A}$ variety of patient resources exist for smoking cessation, ranging from pharmacological to behavioral. The American Lung Association has a website that lists resources for patients interested in smoking cessation (http://www.lung.org/stop-smoking/how-to-quit/ getting-help/). Serious illnesses, such as lower respiratory tract infections, and death due to influenza in COPD patients, can be prevented by annual vaccinations against the prevalent strain of influenza. ${ }^{7}$ Similarly, the pneumococcal polysaccharide vaccine is recommended in patients with COPD. ${ }^{7}$

PR also deserves special emphasis. PR involves multidisciplinary care, including patient assessment and education, exercise training, and psychosocial support, usually conducted in an outpatient setting. ${ }^{22}$ PR improves exercise capacity, shortness of breath, health-related quality of life (QOL), and health care utilization, ${ }^{23}$ including significantly reducing hospitalization and mortality even following acute exacerbation. ${ }^{24} \mathrm{PR}$ is underutilized, and although unstable COPD may seem to be a barrier to PR, increases in mobility and exercise capacity may actually help to improve the patient's condition. ${ }^{25}$ 


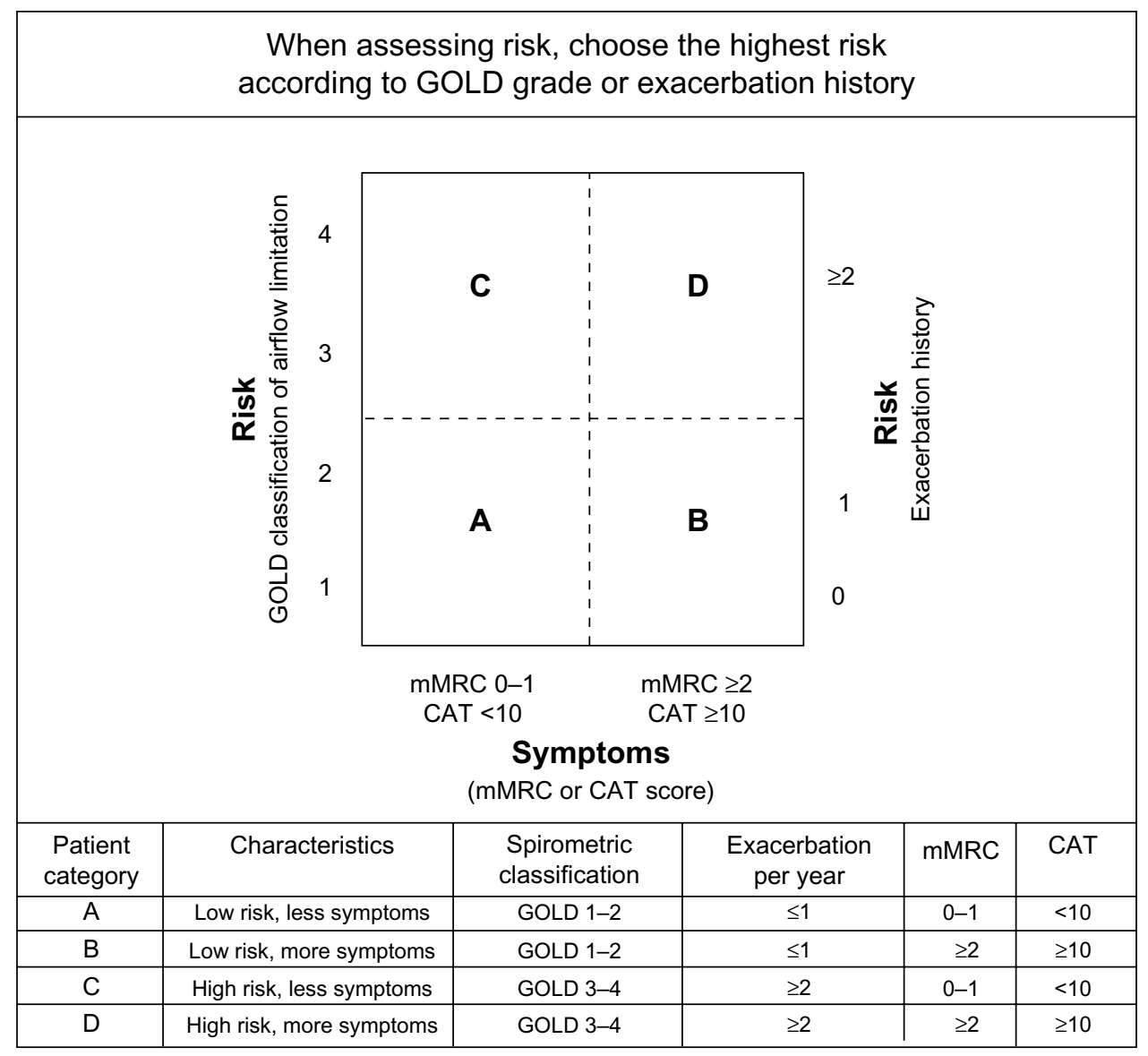

Figure 4 Assessment of COPD using symptoms, spirometric staging, and risk of exacerbations.

Note: From the Global Strategy for Diagnosis, Management, and Prevention of COPD, 2013, available from http://www.goldcopd.org. ${ }^{7}$ Used with permission.

Abbreviations: GOLD, The Global Initiative for Chronic Obstructive Lung Disease; mMRC, modified Medical Research Council; CAT, COPD Assessment Test; COPD, chronic obstructive pulmonary disease.

\section{Pharmacological therapy of COPD}

The goal of pharmacotherapy for COPD is to reduce symptoms, prevent exacerbations, improve exercise tolerance, and improve overall health. ${ }^{7}$ Unfortunately, current medications have not been shown to affect long-term decline in lung function associated with COPD. ${ }^{7}$ Therefore, treatment must be focused on symptom control and must be individualized based on patients' disease severity and risk of exacerbation. ${ }^{7}$ The GOLD strategy for the pharmacotherapy of COPD provides general guidance by grouping patients based on symptoms and risk (Table 2). ${ }^{7}$ In general, the following recommendations should be considered:

- Short-acting beta-agonists may be used for rescue and to treat exacerbations (with or without short-acting anticholinergics). ${ }^{7,26}$

- Long-acting inhaled bronchodilators are preferred over short-acting and oral bronchodilators for maintenance therapy. ${ }^{7}$ Inhaled long-acting beta $_{2}$-agonists, such as salmeterol, formoterol, and indacaterol, are associated with improved outcomes in some COPD patients, including improved lung function, symptoms, and health-related QOL. ${ }^{27}$ The inhaled long-acting anticholinergic agent, tiotropium, is associated with improved lung function and QOL, as well as with decreased risk of exacerbations. ${ }^{28}$ More recently, a second long-acting anticholinergic, aclidinium bromide, was approved for the twice-daily maintenance of COPD. ${ }^{29}$

- Inhaled corticosteroids may be used long-term in combination with long-acting bronchodilators in patients with severe disease who are at high risk of exacerbations, but these medications are not recommended as monotherapy in COPD. ${ }^{7}$

- As is true with all pharmacotherapy, the side effect profiles of all medications must be considered when individualizing treatment.

It is important to note that symptomatic patients should not be relying on rescue medication alone. Increased frequency of use of rescue medication may reflect worsening of the disease. ${ }^{30}$ Nurses may be in a unique position to monitor the use of rescue medication, as they have the opportunity 
Table 2 Pharmacotherapy of COPD based on the patient's grade of disease*

\begin{tabular}{|c|c|c|c|}
\hline Patient group & First choice & Second choice & Alternative choice ${ }^{* *}$ \\
\hline A & $\begin{array}{l}\text { Short-acting anticholinergic prn } \\
\text { or } \\
\text { Short-acting beta }{ }_{2} \text {-agonist prn }\end{array}$ & $\begin{array}{l}\text { Long-acting anticholinergic } \\
\text { or } \\
\text { Long-acting beta } \text {-agonist or } \\
\text { Short-acting beta -agonist and short-acting anticholinergic }\end{array}$ & Theophylline \\
\hline B & $\begin{array}{l}\text { Long-acting anticholinergic } \\
\text { or } \\
\text { Long-acting beta }{ }_{2} \text {-agonist }\end{array}$ & Long-acting anticholinergic and long-acting beta ${ }_{2}$-agonist & $\begin{array}{l}\text { Short-acting beta }{ }_{2} \text {-agonist } \\
\text { and/or } \\
\text { Short-acting anticholinergic } \\
\text { Theophylline }\end{array}$ \\
\hline C & $\begin{array}{l}\text { Inhaled corticosteroid + long- } \\
\text { acting beta }{ }_{2} \text {-agonist } \\
\text { or } \\
\text { Long-acting anticholinergic }\end{array}$ & Long-acting anticholinergic and long-acting beta ${ }_{2}$-agonist & $\begin{array}{l}\text { Phosphodiesterase-4 inhibitor } \\
\text { Short-acting beta } 2 \text {-agonist } \\
\text { and/or } \\
\text { Short-acting anticholinergic } \\
\text { Theophylline }\end{array}$ \\
\hline D & $\begin{array}{l}\text { Inhaled corticosteroid + long- } \\
\text { acting beta }{ }_{2} \text {-agonist } \\
\text { or } \\
\text { Long-acting anticholinergic }\end{array}$ & $\begin{array}{l}\text { Inhaled corticosteroid and long-acting anticholinergic } \\
\text { or } \\
\text { Inhaled corticosteroid + long-acting beta }{ }_{2} \text {-agonist and } \\
\text { long-acting anticholinergic } \\
\text { or } \\
\text { Inhaled corticosteroid + long-acting beta } 2 \text {-agonist and } \\
\text { phosphodiesterase- } 4 \text { inhibitor } \\
\text { or } \\
\text { Long-acting anticholinergic and long-acting beta }{ }_{2} \text {-agonist } \\
\text { or } \\
\text { Long-acting anticholinergic and phosphodiesterase-4 inhibitor }\end{array}$ & $\begin{array}{l}\text { Carbocysteine } \\
\text { Short-acting beta } 2 \text {-agonist } \\
\text { and/or } \\
\text { Short-acting anticholinergic } \\
\text { Theophylline }\end{array}$ \\
\hline
\end{tabular}

Notes: GOLD patient stages are shown in Figure $4 ;{ }^{*}$ medications in each box are mentioned in alphabetical order, and therefore not necessarily in order of preference; **medications in this column can be used alone or in combination with other options in the first and second columns.

From the Global Strategy for Diagnosis, Management, and Prevention of COPD, 2013, available from http://www.goldcopd.org. ${ }^{7}$ Used with permission.

Abbreviations: COPD, chronic obstructive pulmonary disease; prn, pro re nata (as needed); GOLD, Global Initiative for Chronic Obstructive Lung Disease.

to reprioritize care to ensure that COPD is well managed. In many cases, because of their close interactions with patients, nurses can elicit information concerning increases in rescue medication usage, worsening of respiratory symptoms, decline in function, gaps in treatment after discharge for exacerbations, and incorrect use of inhalation devices. Since they can assess these conditions, nurses can help keep COPD therapy a focus of patient care.

\section{Medication delivery systems}

The American Association for Respiratory Care issues guidelines for aerosol delivery devices for the treatment of COPD. ${ }^{31}$ Inhalers (metered-dose inhalers [MDIs] and dry powder inhalers [DPIs]) are the mainstays of treatment for COPD; however, some patients may benefit from nebulized therapy. Novel inhalers are being introduced, and nurses should be familiar with the use of each inhaler device to be able to educate patients. Each device type has its own advantages and disadvantages.

\section{Metered-dose inhalers}

Pressurized MDIs contain a gas that propels the drugs during administration. They are portable and compact, and their treatment time is short. ${ }^{32}$ Their use requires an appropriate inhalation technique, as they involve multiple steps for proper use. ${ }^{31}$ Challenges with MDIs include interposition of the tongue on the mouthpiece, blocking flow, ${ }^{33}$ and improper coordination between device actuation and inspiration. ${ }^{34}$ Factors such as hand strength and cognitive status in older adults may affect the ability of patients to utilize MDIs properly. ${ }^{35}$ Spacer devices may help patients in addressing difficulties using MDIs because of coordination issues, and these devices may improve drug delivery. ${ }^{7}$ However, spacers retain part of every dose and can reduce the dose of drug actually being delivered to the patient. ${ }^{36}$

\section{Dry powder inhalers}

DPIs are breath-activated. They are also portable and compact, and require short treatment times. Their main advantage over MDIs is that they do not require coordination between actuation and inhalation. ${ }^{32}$ DPIs vary by manufacturer and may be multi-dose or single-dose systems; thus, the instructions specific to the device selected should be carefully reviewed with the patient to help ensure proper use. Drugs are delivered from these devices due to inspiratory airflow, rather than being self-propelled, and therefore the user needs to have adequate inspiratory 
capacity (measured in peak inspiratory flow rate) to use them effectively and to receive the full dose. Patients who are below the minimum peak inspiratory flow rate threshold required for each device cannot generate enough force to inhale the drug. ${ }^{37}$ A small study of elderly patients and matched controls found that peak inspiratory flow was compromised among elderly patients, regardless of COPD. ${ }^{38}$ In addition to limited inspiratory force, patients may exhale (blow) into the mouthpiece, with the consequent loss of part of the powder. ${ }^{32}$ Patients may also incorrectly position the inhaler or the mouthpiece. ${ }^{39}$

\section{Nebulizers}

Nebulized therapy may be an alternative for patients who cannot use the other devices. In addition, some patients prefer to use a nebulizer over a handheld device. ${ }^{40}$ A key advantage is that these devices only require tidal breathing, ${ }^{32}$ making them a possible alternative for patients with cognitive alterations or who lack sufficient inspiratory capacity to use either MDIs or DPIs. ${ }^{32,41}$ While in the past nebulizers were usually bulky devices, smaller nebulizers are now available, including portable (battery-operated) devices. Nebulizers require a longer time to use than MDIs or DPIs, and they must be prepared before use, and cleaned after use. $^{41}$

\section{Selection of delivery device}

The choice of an inhaler depends on several factors, including cost, preference of the prescribing clinician, and the patient's ability to use the inhaler. ${ }^{7}$ Some groups of patients may be at risk of suboptimal use of handheld inhalers, and they may benefit instead from nebulized therapy (Table 3). ${ }^{41}$ Cognitive impairment may be more common among COPD patients than among healthy patients, ${ }^{42}$ and this may affect some patients' ability to use MDIs or DPIs properly. When a patient is identified as needing nebulized therapy, this should not only be done for the rescue medication, but also for maintenance with nebulized long-acting agents. Nurses are in a key position to help identify which delivery device would work best for a given patient.

Table 3 Patients for whom nebulized therapy might be beneficial

- Cognitively impaired

- Impaired manual dexterity

- Muscle weakness

- Unable to follow directions or noncompliant

- Inadequate symptom relief with an inhaler

- Patient's preference

Note: Data from Dhand et al. ${ }^{41}$

\section{Barriers to effective management of COPD}

Despite the existence of several evidence-based guidelines for the diagnosis, staging, and treatment of COPD, ${ }^{7,10}$ barriers have been described that inhibit full adherence to these guidelines. For example, physician knowledge and familiarity with the COPD guidelines may be lower than it is for treatment guidelines of other chronic conditions. Salinas et $\mathrm{al}^{43}$ surveyed 309 primary care physicians and found that $<30 \%$ were "very familiar" with the GOLD guidelines. In contrast, nearly $80 \%$ reported being "very familiar" with the Joint National Committee on Prevention, Detection, Evaluation, and Treatment of High Blood Pressure. Yawn and Wollan ${ }^{14}$ surveyed primary care physicians, nurse practitioners, and physician assistants, and they found that only $31 \%$ of physicians and $34 \%$ of nurse practitioners/physician assistants used published guidelines for the diagnosis of COPD. Other barriers to the diagnosis of COPD cited in this study included the failure of patients to recognize and report dyspnea, a lack of access to spirometry, a lack of knowledge about COPD, a lack of training regarding its diagnosis and treatment, and the perception that treatment was ineffective. COPD-specific medical education programs that adhere to the American College of Chest Physicians Evidence-Based Educational Guidelines $^{44}$ have been reported to increase the likelihood of physician adherence to current guidelines in the management of COPD. ${ }^{45}$

The lack of patient education and active participation in the management of their disease is also an impediment to the effective treatment of COPD. Patients are reported to be generally uninformed about the treatment of COPD and the consequences of exacerbations. ${ }^{46,47}$ Improved communication during office visits and COPD self-management education may improve patient care and patients' satisfaction with treatment. ${ }^{47,48}$

An educated patient who actively participates in the selfmanagement of COPD and in the delivery of patient-centric treatment that adheres to evidence-based guidelines are two of the most important components of the chronic care model (CCM) of the management of chronic diseases. ${ }^{49}$ Although the CCM has been associated with improved outcomes for patients with diabetes and asthma, ${ }^{50}$ little data exist supporting its implementation in the management of the COPD. Adams et $\mathrm{a}^{51}$ performed a systematic review of the CCM in COPD and found no effect of the CCM on symptoms, QOL, lung function, or functional status in 32 heterogeneous studies that incorporated one or more components of the CCM. However, their pooled analysis of three studies investigating 
self-management education provided by nurses in addition to advanced access to care, adherence to guidelines, and communication between the treating physician and nurse, revealed a significant reduction in the risk of emergency department or unscheduled visits for intervention. Similarly, a pooled analysis of studies incorporating multiple components of the CCM found a significantly reduced risk of hospitalization, whereas studies that reported using only a single component of the CCM did not. The authors concluded that their results highlighted the need for well-designed clinical studies of the CCM in COPD.

\section{Management of comorbidities}

COPD can complicate the course of other diseases. It is well documented that the hypoxia generated by COPD may affect all organ systems, and it often worsens other comorbidities (for example, cognitive impairment, ${ }^{42}$ cardiovascular disease, and diabetes). ${ }^{7}$ Several comorbidities may also complicate the course of COPD. Importantly, time spent on comorbidities during a standard office visit may reduce the time allocated to the diagnosis and treatment of COPD. This is especially relevant for clinicians who do not use spirometry, thus limiting COPD management to clinical interactions. It is important to note that COPD is associated with high rates of morbidity and mortality (it is the third-leading cause of death), which are sometimes higher than in other conditions. Therefore, COPD should have high priority in the management hierarchy during office visits.

\section{Optimizing care for COPD patients}

COPD is a progressive disease, and nurses can have a major impact on patients' symptoms and QOL through appropriate patient assessment, communication with the clinical team, and implementation of proper management (Table 4). The role of nurse-led consultations with patients has become more important in the management of COPD, and nurse-led education and intervention programs have been reported to improve patient knowledge, increase the rate of smoking cessation, and reduce the frequency of exacerbations. ${ }^{52}$ The following is a summary of best practices.

\section{Identifying patients at risk}

Consider a diagnosis of COPD in patients with risk factors, especially those who are symptomatic (those with shortness of breath, sputum production, and/or chronic cough). Evaluate these patients using spirometry whenever possible, rather than just making a clinical diagnosis.
Table 4 Optimizing care for COPD patients

- Prevent

- Smoking cessation and avoid exposures to environmental tobacco smoke and other air pollutants

- Respiratory infections (vaccination)

- Suspect and diagnose

- Identify patients at risk (history of smoking, environmental or occupational exposures with shortness of breath, sputum production, and/or chronic cough)

- Investigate

- Intervene early

- Early intervention produces better results

- Use of pulmonary rehabilitation for disabling symptoms

- Manage attentively

- Regular, consistent follow-up

- Look for signs of worsening (for example, increased rescue use, worsening of symptoms, decline in function, hypoxemia)

- Assess adherence and inhaler technique at every visit

- Consider nebulization for physically/cognitively impaired, elderly, or frail patients who may have trouble with adherence

- Manage within scope of comorbidities

- Pay attention to COPD; do not let other conditions (hypertension, diabetes, hypercholesterolemia, and so on) take all the time spent with a patient

Abbreviation: COPD, chronic obstructive pulmonary disease.

\section{Smoking cessation is a cornerstone of the prevention of COPD}

Smoking cessation programs and medications are available and may help patients quit.

\section{Intervene early in your symptomatic patients with COPD}

Treat early in the disease process. Accumulating evidence indicates that earlier intervention in treating COPD patients may be beneficial. ${ }^{53}$

\section{Manage COPD attentively}

Manage your patients on an ongoing basis while they are stable. Do not wait for an exacerbation or pneumonia to present to begin managing COPD. Consistently monitor your patients with COPD for any indication of worsening symptoms (for example, increased use of rescue medication, or worsening of respiratory symptoms). Follow your patients as frequently as their condition demands. Patients with more severe disease, or in whom adherence with therapy may be an issue, are a priority for ongoing follow-up.

Focus not only on respiratory symptoms, but also on the patient's functional level. Ask "How are you doing?" and "What are you doing, physically?" as a way of evaluating the effect of COPD on a patient's function and symptoms. ${ }^{54}$ Using the CAT questionnaire (Figure 2) over time may be 
helpful for identifying a patient's decline, and it may also act as a platform for collaborating with patients on managing their disease.

Ensure proper pharmacotherapy. Individualize pharmacotherapy based on patient characteristics, including his or her severity of COPD. Manage medications to prevent exacerbations. Patients should not be relying on rescue medication alone, and nurses can identify this situation early.

Assess inhaler technique. Assess inhaler technique at every visit to make sure your patient is using the inhaler correctly. ${ }^{7}$ After two unsuccessful attempts during office visits to train a patient in inhaler use, consider switching to nebulized therapy. Early identification of patients who are, or are becoming, physically/cognitively impaired or frail, and who may have difficulty physically using an inhaler or following instructions, can help to promote better adherence with treatment. Evaluating patients for cognitive impairment can be done through informal discussions to evaluate their mental capacity. There are also formal evaluations that can be done (for example, fall risk assessment testing with components that reflect cognitive function).

Cognitively impaired patients may benefit from nebulized therapy because of their inability to properly use inhalers. In addition, frail/elderly patients may not be able to follow instructions on how to use handheld inhalers (MDIs/DPIs), or they may be able to understand instructions during an office visit but not remember them afterwards.

Look for other ways to improve adherence. Try to address or remove barriers to adherence, such as financial burdens, complexity of care, and polypharmacy. Disease education can help make it clear to your patients that COPD is chronic and that ongoing management helps in the long-term. Consider motivational interviewing to enhance your patient's drive and confidence in self-management. As with any condition, be aware that patients may hide or deny symptoms or simply not recognize them, so nurses must help patients to be objective about their symptoms.

\section{Assess and manage comorbidities}

Manage comorbidities in COPD patients, but do not allow COPD to be neglected while managing other conditions. Proper management of COPD may aid in the management of comorbidities.

\section{Conclusion}

In conclusion, while COPD is a challenging and progressive condition, you can make a difference in your patients' clinical course by identifying the disease early and managing it attentively. Helping your patients to quit smoking, properly use medications, and embrace PR can all contribute to better outcomes. Partnering with your patients over time and monitoring them closely can help to optimize care.

\section{Acknowledgments}

The authors acknowledge the writing and editorial assistance provided by Jonathan Cargan, MD, of PharmaWrite, LLC (Princeton, NJ, USA). This manuscript was prepared according to the International Society for Medical Publication Professionals' "Good Publication Practice for Communicating Company-Sponsored Medical Research: the GPP2 Guidelines." Funding to support the preparation of this manuscript was provided by Mylan Specialty LP.

\section{Disclosure}

$\mathrm{CG}$ has received consultation fees from Boehringer Ingelheim, Pfizer, and Sepracor, and is a speakers' bureau member for Boehringer Ingelheim. NAH received honoraria for serving as a consultant and on the speakers' bureau for Mylan Specialty LP. His institution received research grant support from Mylan Specialty LP. At the time of completion of the manuscript, PA was a full-time employee of Mylan Specialty LP. The authors report no other conflicts of interest in this work.

\section{References}

1. World Health Organization [webpage on the Internet]. The top 10 causes of death. Geneva, Switzerland: World Health Organization; 2013. Available from: http://www.who.int/mediacentre/factsheets/fs310/en/ index.html. Accessed August 2, 2013.

2. World Health Organization [webpage on the Internet]. Chronic obstructive pulmonary disease (COPD). Geneva, Switzerland: World Health Organization; 2013. Available from: http://www.who.int/mediacentre/ factsheets/fs315/en. Accessed August 12, 2013.

3. Heron M. Deaths: leading causes for 2008. Natl Vital Stat Rep. 2012; 60(6):1-94.

4. National Institutes of Health. Morbidity and Mortality: 2012 Chartbook on Cardiovascular, Lung, and Blood Diseases. Bethesda, MD: National Institutes of Health; 2012.

5. Mannino DM, Homa DM, Akinbami LJ, Ford ES, Redd SC. Chronic obstructive pulmonary disease surveillance - United States, 1971-2000. MMWR Surveill Summ. 2002;51(6):1-16.

6. Barr RG, Celli BR, Mannino DM, et al. Comorbidities, patient knowledge, and disease management in a national sample of patients with COPD. Am J Med. 2009;122(4):348-355.

7. Global Initiative for Chronic Obstructive Lung Disease. Global Strategy for the Diagnosis, Management, and Prevention of Chronic Obstructive Pulmonary Disease (Updated 2013). Global Initiative for Chronic Obstructive Lung Disease, Inc; Vancouver, Washington 2013.

8. Han MK, Kim MG, Mardon R, et al. Spirometry utilization for COPD: how do we measure up? Chest. 2007;132(2):403-409.

9. Belfer MH. Office management of COPD in primary care: a 2009 clinical update. Postgrad Med. 2009;121(4):82-90. 
10. Qaseem A, Wilt TJ, Weinberger SE, et al; American College of Physicians; American College of Chest Physicians; American Thoracic Society; European Respiratory Society. Diagnosis and management of stable chronic obstructive pulmonary disease: a clinical practice guideline update from the American College of Physicians, American College of Chest Physicians, American Thoracic Society, and European Respiratory Society. Ann Intern Med. 2011;155(3):179-191.

11. Hanania NA, Mannino DM, Yawn BP, et al. Predicting risk of airflow obstruction in primary care: Validation of the lung function questionnaire (LFQ). Respir Med. 2010;104(8):1160-1170.

12. Martinez FJ, Raczek AE, Seifer FD, et al. COPD-PS Clinician Working Group. Development and initial validation of a self-scored COPD Population Screener Questionnaire (COPD-PS). COPD. 2008;5(2): 85-95.

13. Jones PW, Harding G, Berry P, Wiklund I, Chen WH, Kline LN. Development and first validation of the COPD Assessment Test. Eur Respir J. 2009;34(3):648-654.

14. Yawn BP, Wollan PC. Knowledge and attitudes of family physicians coming to COPD continuing medical education. Int J Chron Obstruct Pulmon Dis. 2008;3(2):311-317.

15. Bestall JC, Paul EA, Garrod R, Garnham R, Jones PW, Wedzicha JA. Usefulness of the Medical Research Council (MRC) dyspnoea scale as a measure of disability in patients with chronic obstructive pulmonary disease. Thorax. 1999;54(7):581-586.

16. Donaldson GC, Seemungal TA, Bhowmik A, Wedzicha JA. Relationship between exacerbation frequency and lung function decline in chronic obstructive pulmonary disease. Thorax. 2002;57(10):847-852.

17. Kelly C. An overview of acute exacerbations of COPD: assessing and preventing acute exacerbations of COPD. Nurs Times. 2009;105(13): 25-26, 28.

18. Langsetmo L, Platt RW, Ernst P, Bourbeau J. Underreporting exacerbation of chronic obstructive pulmonary disease in a longitudinal cohort. Am J Respir Crit Care Med. 2008;177(4):396-401.

19. Nici L, Donner C, Wouters E, et al; ATS/ERS Pulmonary Rehabilitation Writing Committee. American Thoracic Society/European Respiratory Society statement on pulmonary rehabilitation. Am J Respir Crit Care Med. 2006;173(12):1390-1413.

20. Hurst JR, Vestbo J, Anzueto A, et al; Evaluation of COPD Longitudinally to Identify Predictive Surrogate Endpoints (ECLIPSE) Investigators. Susceptibility to exacerbation in chronic obstructive pulmonary disease. N Engl J Med. 2010;363(12):1128-1138.

21. Kohansal R, Martinez-Camblor P, Agustí A, Buist AS, Mannino DM, Soriano JB. The natural history of chronic airflow obstruction revisited: an analysis of the Framingham offspring cohort. Am J Respir Crit Care Med. 2009;180(1):3-10.

22. Nici L, Lareau S, ZuWallack R. Pulmonary rehabilitation in the treatment of chronic obstructive pulmonary disease. Am Fam Physician. 2010;82(6):655-660.

23. ZuWallack R, Hedges H. Primary care of the patient with chronic obstructive pulmonary disease-part 3: pulmonary rehabilitation and comprehensive care for the patient with chronic obstructive pulmonary disease. Am J Med. 2008;121(Supp1 7):S25-S32.

24. Puhan MA, Gimeno-Santos E, Scharplatz M, Troosters T, Walters EH, Steurer J. Pulmonary rehabilitation following exacerbations of chronic obstructive pulmonary disease. Cochrane Database Syst Rev. 2011;(10):CD005305.

25. Garvey C, Fromer L, Saver DF, Yawn BP. Pulmonary rehabilitation: an underutilized resource in primary COPD care. Phys Sportsmed. 2010;38(4):54-60.

26. Garvey C. Best practices in chronic obstructive pulmonary disease. Nurse Pract. 2011;36(5):16-22; quiz 22-23.

27. Tashkin DP, Fabbri LM. Long-acting beta-agonists in the management of chronic obstructive pulmonary disease: current and future agents. Respir Res. 2010;11:149.

28. Tashkin DP, Celli B, Senn S, et al; UPLIFT Study Investigators. A 4-year trial of tiotropium in chronic obstructive pulmonary disease. N Engl J Med. 2008;359(15):1543-1554.
29. US Food and Drug Administration [webpage on the Internet]. FDA approves Tudorza Pressair to treat chronic obstructive pulmonary disease. Silver Spring, MD: US Food and Drug Administration; 2012. Available from: http://www.fda.gov/NewsEvents/Newsroom/ PressAnnouncements/ucm313052.htm. Accessed March 6, 2013.

30. Sharafkhaneh A, Hanania NA, Colice GL, et al. A simple rule to identify COPD patients who may need treatment re-evaluation based on SABA use. In: American Thoracic Society International Conference Abstracts; May 18-23, 2012; San Francisco, CA. Abstract C106.

31. Ari A, Hess D, Myers TR, Rau JL. A Guide to Aerosol Delivery Devices for Respiratory Therapy. 2nd ed. Irving, TX: American Association for Respiratory Care; 2009.

32. Dolovich MB, Dhand R. Aerosol drug delivery: developments in device design and clinical use. Lancet. 2011;377(9770):1032-1045.

33. Broeders ME, Sanchis J, Levy ML, Crompton GK, Dekhuijzen PN; ADMIT Working Group. The ADMIT series - issues in inhalation therapy. 2. Improving technique and clinical effectiveness. Prim Care Respir J. 2009;18(2):76-82.

34. Fromer L, Goodwin E, Walsh J. Customizing inhaled therapy to meet the needs of COPD patients. Postgrad Med. 2010;122(2):83-93.

35. Gray SL, Williams DM, Pulliam CC, Sirgo MA, Bishop AL, Donohue JF. Characteristics predicting incorrect metered-dose inhaler technique in older subjects. Arch Intern Med. 1996;156(9):984-988.

36. Rau JL. Practical problems with aerosol therapy in COPD. Respir Care. 2006;51(2):158-172.

37. Atkins PJ. Dry powder inhalers: an overview. Respir Care. 2005;50(10): 1304-1312; discussion 1312.

38. Janssens W, VandenBrande $\mathrm{P}$, Hardeman $\mathrm{E}$, et al. Inspiratory flow rates at different levels of resistance in elderly COPD patients. Eur Respir J. 2008;31(1):78-83.

39. Lavorini F, Magnan A, Dubus JC, et al. Effect of incorrect use of dry powder inhalers on management of patients with asthma and COPD. Respir Med. 2008;102(4):593-604.

40. Sharafkhaneh A, Wolf RA, Goodnight S, Hanania NA, Make BJ, Tashkin DP. Perceptions and attitudes toward the use of nebulized therapy for COPD: patient and caregiver perspectives. COPD. 2013;10(4):482-492.

41. Dhand R, Dolovich M, Chipps B, Myers TR, Restrepo R, Farrar JR. The role of nebulized therapy in the management of COPD: evidence and recommendations. COPD. 2012;9(1):58-72.

42. Thakur N, Blanc PD, Julian LJ, et al. COPD and cognitive impairment: the role of hypoxemia and oxygen therapy. Int J Chron Obstruct Pulmon Dis. 2010;5:263-269.

43. Salinas GD, Williamson JC, Kalhan R, et al. Barriers to adherence to chronic obstructive pulmonary disease guidelines by primary care physicians. Int J Chron Obstruct Pulmon Dis. 2011;6: $171-179$.

44. Moores LK, Dellert E, Baumann MH, Rosen MJ; American College of Chest Physicians Health and Science Policy Committee. Executive summary: effectiveness of continuing medical education: American College of Chest Physicians Evidence-Based Educational Guidelines. Chest. 2009;135(Suppl 3):1S-4S.

45. Drexel C, Jacobson A, Hanania NA, Whitfield B, Katz J, Sullivan T. Measuring the impact of a live, case-based, multiformat, interactive continuing medical education program on improving clinician knowledge and competency in evidence-based COPD care. Int J Chron Obstruct Pulmon Dis. 2011;6:297-307.

46. Barr RG, Celli BR, Martinez FJ, et al. Physician and patient perceptions in COPD: the COPD Resource Network Needs Assessment Survey. Am J Med. 2005;118(12):1415.

47. Hernandez P, Balter M, Bourbeau J, Hodder R. Living with chronic obstructive pulmonary disease: a survey of patients' knowledge and attitudes. Respir Med. 2009;103(7):1004-1012.

48. Nelson M, Hamilton HE. Improving in-office discussion of chronic obstructive pulmonary disease: results and recommendations from an in-office linguistic study in chronic obstructive pulmonary disease. $\mathrm{Am}$ J Med. 2007;120(8 Suppl 1):S28-S32. 
49. Wagner EH, Bennett SM, Austin BT, Greene SM, Schaefer JK, Vonkorff M. Finding common ground: patient-centeredness and evidence-based chronic illness care. J Altern Complement Med. 2005; 11 Suppl 1:S7-S15.

50. Bodenheimer $\mathrm{T}$, Wagner $\mathrm{EH}$, Grumbach $\mathrm{K}$. Improving primary care for patients with chronic illness. JAMA. 2002;288(14):1775-1779.

51. Adams SG, Smith PK, Allan PF, Anzueto A, Pugh JA, Cornell JE. Systematic review of the chronic care model in chronic obstructive pulmonary disease prevention and management. Arch Intern Med. 2007;167(6):551-561.
52. Fletcher MJ, Dahl BH. Expanding nurse practice in COPD: is it key to providing high quality, effective and safe patient care? Prim Care Respir J. 2013;22(2):230-233.

53. Decramer M, Cooper CB. Treatment of COPD: the sooner the better? Thorax. 2010;65(9):837-841.

54. ZuWallack R. How are you doing? What are you doing? Differing perspectives in the assessment of individuals with COPD. COPD. 2007;4(3):293-297.

Nursing: Research and Reviews

\section{Publish your work in this journal}

Nursing: Research and Reviews is an international, peer-reviewed, open access journal publishing original research, reports, reviews and commentaries on all aspects of nursing and patient care. These include patient education and counselling, ethics, management and organizational issues, diagnostics and prescribing, economics and

\section{Dovepress}

Submit your manuscript here: http://www.dovepress.com/nursing-research-and-reviews-journal

resource management, health outcomes, and improving patient safety in all settings. The manuscript management system is completely online and includes a very quick and fair peer-review system. Visit http://www.dovepress.com/testimonials.php to read real quotes from published authors. 